\title{
Clinical Features and Outcome of Low and High Corticosteroids in Admitted COVID-19 Patients
}

\author{
Salma AlBahrani ${ }^{1,2}$, Jaffar A. Al-Tawfiq ${ }^{3,4,5, *},(\mathbb{D})$, Arulanantham Zachariah Jebakumar ${ }^{6}$ (D), Mohammed Alghamdi ${ }^{1}$, \\ Nawaf Zakary ${ }^{1}$, Mariam Seria ${ }^{1}$, Abdulrahman Alrowis ${ }^{1}$ \\ ${ }^{1}$ Department of Medicine, King Fahad Military Medical Complex, Dhahran, Saudi Arabia \\ ${ }^{2}$ Infectious Disease Unit, King Fahad Military Medical Complex, Dhahran, Saudi Arabia \\ ${ }^{3}$ Infectious Disease Unit, Specialty Internal Medicine, Johns Hopkins Aramco Healthcare, Dhahran 31311, Saudi Arabia \\ ${ }^{4}$ Infectious Disease Division, Department of Medicine, Indiana University School of Medicine, Indianapolis, IN, USA \\ ${ }^{5}$ Infectious Disease Division, Department of Medicine, Johns Hopkins University School of Medicine, Baltimore, MD, USA \\ ${ }^{6}$ Postgraduate Studies and Research, Prince Sultan Military College of Health Sciences, Dhahran, Saudi Arabia
}

\section{ARTICLE INFO}

Article History

Received 07 March 2021

Accepted 21 May 2021

Keywords

SARS-CoV-2

COVID-19

steroid

high-dose steroid

\section{ABSTRACT}

Introduction: There is no specific anti-viral therapies for 2019 Coronavirus Diseases (COVID-19) infection. Here, we compared patients receiving steroids at different dosages versus no steroids in severe and critical COVID-19 patients.

Methods: We retrospectively studied COVID-19 patients who received low-dose or high-dose corticosteroid therapy compared to no steroid.

Results: The study period, June-August 2020, included 169 patients with COVID-19 were included and there were $39.1 \%$ female and $60.9 \%$ male with an average age of 53.1 years. The distribution of cases was as follows: high-dose 39 (23.1\%), low-dose $54(32.0 \%)$, and no steroid 76 (45.5\%). Of all the patients, Intensive Care Unit (ICU) admission was for 31 (18.3\%), nine (5.3\%) required intubation, and $52(30.8 \%)$ had no comorbidities. There is no difference in the mean age between the different groups. However, those being treated with steroid were more likely to have a high sequential organ failure assessment (SOFA) score ( 0.37 $\pm 0.68,0.36 \pm 0.67$ and $0.04 \pm 0.34$, for low-dose, high-dose steroid and no steroid groups, respectively $(p=0.001)$. Cox regression was not possible as the mortality rate was very low $(3 / 169 ; 1.78 \%)$ and none of the multivariate methods would be possible. However, there was a significant difference in the hospital Length of stay (LOS) and the ICU LOS.

Conclusion: Cox regression was not possible as the mortality rate was very low (1.78\%) and none of the multivariate methods would be possible as the model will not converge. However, in $t$-test only, intubation was associated risk of mortality.

(C) 2021 The Authors. Published by Atlantis Press International B.V.

This is an open access article distributed under the CC BY-NC 4.0 license (http://creativecommons.org/licenses/by-nc/4.0/).

\section{INTRODUCTION}

The emergence of the Severe Acute Respiratory Syndrome Coronavirus 2 (SARS-CoV-2) had resulted in a clinical spectrum of SARS-CoV-2 infection. Patients may present with symptoms ranging from mild to severe infection requiring intensive care unit admission. In addition, asymptomatic infections were also described [1-6]. The need for Intensive Care Unit (ICU) admission is estimated to be 5\% with increased mortality compared to those who do not require ICU admission [7,8]. The physiologic description of the 2019 Coronavirus Diseases (COVID-19) consists of an initial viral replication phase and then the immune system reactions would lead to the development of inflammatory responses with a wide range of clinical findings $[9,10]$. The second phase of immune response may lead to a disproportionate and unregulated cytokine releasing storm resulting and subsequent emergence of acute respiratory distress syndrome, and death [11-13]. Based on the clinical presentation and the pathophysiology of COVID-19, the case fatality rates varies from $61.5 \%$ in those requiring intensive care admission in earlier studies [14] and may be lower as cited in more recent studies of a fatality rate of $25.8 \%$ [15].
Multiple studies across the world had included multiple interventions to cure SARS-CoV-2 infections. However, the main stay of therapy of such patients relies on supportive care [16]. It is also important to use immunomodulatory agents to treat cytokine releasing storm and this is being studies as well [16] as the use of corticosteroid therapy $[10,16,17]$. The landmark of steroid therapy in COVID-19 patients is the RECOVERY trial which utilized dexamethasone at a dose of $6 \mathrm{mg}$ intravenous or oral once a day [18]. In the Kingdom of Saudi Arabia, studies had been conducted to describe the epidemiology and clinical features including those who required ICU admission and those who were cared for in quarantine facilities [4-6,8,19]. Here, we sought to further evaluate the utilization and effect of highand low-dose of corticosteroids in comparison to no-steroid therapy in patients with severe and critical conditions of COVID-19.

\section{MATERIALS AND METHODS}

This is a retrospective study of COVID-19 patients who received systemic corticosteroids and those were compared to no steroid therapy. Initial patients did not receive steroid and subsequent patients were given corticosteroid based on the results from the RECOVERY trial (6 mg p.o./i.v. once per day) in June 2020. Then 
in mid-July 2020, high-dose corticosteroid was used based on the hospital COVID-19 team consensus of slow clinical response in relation with low dexamethasone dosage.

High-dose weight-based dexamethasone dose was $0.1-0.2 \mathrm{mg} / \mathrm{kg} /$ day for moderate to severe illness and $0.2-0.4 \mathrm{mg} / \mathrm{kg} / \mathrm{day}$ for critically ill. Methylprednisolone dose was $0.5-1 \mathrm{mg} / \mathrm{kg} /$ day for moderate to severe illness and $1-2 \mathrm{mg} / \mathrm{kg} /$ day for critically ill. Prednisone dose was $0.6-1.2 \mathrm{mg} / \mathrm{kg} /$ day for moderate to severe illness and $1.2-2.5 \mathrm{mg} / \mathrm{kg} /$ day. These doses were adjusted per use in connective tissue disease/autoimmune diseases. The indication for the use of steroid was per Infectious Diseases Society of America (IDSA) therapy recommendation in hospitalized with severe illness $\left(\mathrm{O}_{2}\right.$ saturation $\leq 94 \%$ on room air, the requirement of supplemental oxygen, mechanical ventilation or extracorporeal membrane oxygenation).

We collected the demographic of the patients, reviewed medical history, laboratory findings, chest radiology, medication use and clinical outcomes during the administering of glucocorticoids. The study was approved by the Institutional Review Board (IRB) of the King Fahad Military Medical Complex (AFHER-IRB-2020-032).

\subsection{Statistical Analysis}

Descriptive analysis was used for qualitative and quantitative variables. Then further statistical analysis was performed using correlation between variables and patient outcomes. Cox regression model was used to calculate Hazard Ratio (HRs) and 95\% Confidence Intervals (CIs).

The demographic characters were compared between three groups (low steroid, high steroid and no steroid) using statistical tests such as ANOVA ( $F$-test) and Chi-square test, as appropriate. All statistical tests will be two-sided. A $p$-value of $\leq 0.05$ was considered statistically significant.

\section{RESULTS}

During the study period from June to August 2020, 169 patients with COVID-19 were included and there were $39.1 \%$ female and $60.9 \%$ male (Table 1). The average age was 53.1 with standard deviation 16.7. The distribution of the patients was as follows: High-dose 39 (23.1\%), low-dose 54 (32.0\%), and no steroid 76 (45.5\%). Of all the patients, $103(60.9 \%)$ were male, ICU admission for 31 (18.3\%), nine (5.3\%) required intubation, and $52(30.8 \%)$ had no comorbidities. The other patients (68.2\%) had comorbidities as shown in Table 1.

The differences in the characteristics of the patients in the different groups are shown in Table 2 . Those who received steroid were more

Table 1 Socio-demographic characteristics of the cohort of the COVID-19 positive cases $(n=169)$

\begin{tabular}{lcc}
\hline Demographic characters & Frequency & Percentage \\
\hline Male & 103 & 60.9 \\
Female & 66 & 39.1 \\
High-dose steroid & 39 & 23.1 \\
Low-dose steroid & 54 & 32 \\
No steroid & 76 & 45 \\
ICU admission & 31 & 18.3 \\
Intubated & 9 & 5.3 \\
Without intubation & 160 & 94.7 \\
With oxygen & 92 & 54.4 \\
Without oxygen & 77 & 45.6 \\
Bronchial asthma & 6 & 3.6 \\
Diabetes mellitus & 21 & 12.4 \\
Hypertension & 73 & 43.2 \\
Obesity & 9 & 5.3 \\
SCD & 5 & 3 \\
SLE & 3 & 1.8 \\
No comorbidities & 52 & 30.8 \\
\hline
\end{tabular}

SCD, Sickle cell disease; SLE, Systemic lupus erythematosus.

Table 2 A comparison between the different groups (low-dose steroid, high-dose steroid and no steroid group)

\begin{tabular}{|c|c|c|c|c|}
\hline Demographic characters & Low-dose steroid & High-dose steroid & No steroid group & $p$ \\
\hline Male & $37(68.5 \%)$ & $28(71.8 \%)$ & $38(50 \%)$ & 0.03 \\
\hline Female & $17(31.5 \%)$ & $11(28.2 \%)$ & $38(50 \%)$ & \\
\hline ICU admission & $18(33.3)$ & $12(30.8)$ & $1(1.3)$ & $<0.0001$ \\
\hline Intubation & $7(13)$ & $2(5.1)$ & 0 & 0.005 \\
\hline Initial $\mathrm{O}_{2}$ requirement & $45(83.3)$ & $38(97.4)$ & $9(11.8)$ & $<0.0001$ \\
\hline \multicolumn{5}{|l|}{ Comorbidity } \\
\hline Bronchial asthma & $1(1.9)$ & $3(7.7)$ & $2(2.6)$ & $<0.0001$ \\
\hline Diabetes mellitus & $9(16.7)$ & $2(5.1)$ & $10(13.2)$ & \\
\hline Hypertension & $27(50)$ & $18(46.2)$ & $28(36.8)$ & \\
\hline Obesity & $2(3.7)$ & $6(15.4)$ & $1(1.3)$ & \\
\hline Sickle cell disease & 0 & $1(2.6)$ & $4(5.2)$ & \\
\hline Systemic lupus erythematosus & 0 & $1(2.6)$ & $2(2.6)$ & \\
\hline No comorbidities & $15(27.8)$ & $8(20.5)$ & $29(38.2)$ & \\
\hline Age mean $(\mathrm{SD})$ & $55.65(16.95)$ & $54.18(15.67)$ & $50.71(16.97)$ & $F$-value $1.49(p=0.23)$ \\
\hline SOFA score mean (SD) & $0.37(0.68)$ & $0.36(0.67)$ & $0.04(0.34)$ & 0.001 \\
\hline Hospital LOS mean (SD) & $10.30(17.56)$ & $5.95(6.26)$ & $2.97(2.18)$ & 0.001 (F-test) \\
\hline ICU LOS mean (SD) & $18(58.1)$ & $12(38.7)$ & $1(3.2)$ & $<0.0001$ \\
\hline Initial oxygen requirement & $45(83.3)$ & $38(97.4)$ & $9(9.8)$ & $<0.0001$ \\
\hline Hydroxychloroquine & $19(35.2)$ & $10(25.6)$ & $20(26.3)$ & 0.48 \\
\hline Azithromycin & $49(90.7)$ & $36(92.3)$ & $57(75)$ & 0.02 \\
\hline Favipiravir & $2(3.7)$ & $8(20.5)$ & $1(1.3)$ & 0.000 \\
\hline $\begin{array}{l}\text { Triple therapy (PEGylated interferon, } \\
\text { ribavirin, lopinavir/ritonavir) }\end{array}$ & $16(29.6)$ & $1(2.6)$ & 0 & $<0.0001$ \\
\hline Death & 0 & $1(33.3 \%)$ & $2(66.7 \%)$ & 0.49 \\
\hline
\end{tabular}


Table 3 Risk of death in relation to multiple factors using Chi-square test

\begin{tabular}{|c|c|c|c|}
\hline \multirow{2}{*}{$\begin{array}{l}\text { Parameters } \\
\text { associated with } \\
\text { status }\end{array}$} & \multicolumn{2}{|c|}{ Status } & \multirow{2}{*}{$\begin{array}{c}\text { Chi-square } \\
(p \text {-value })\end{array}$} \\
\hline & Alive & Dead & \\
\hline \multicolumn{4}{|l|}{ Comorbidities } \\
\hline Bronchial asthma & $6(100)$ & 0 & $4.02(0.67)$ \\
\hline Diabetes mellitus & $21(100)$ & 0 & \\
\hline Hypertension & $70(95.9)$ & $3(4.1)$ & \\
\hline Obesity & $9(100)$ & 0 & \\
\hline Sickle cell disease & $5(100)$ & 0 & \\
\hline $\begin{array}{l}\text { Systemic lupus } \\
\text { erythematosus }\end{array}$ & $3(100)$ & 0 & \\
\hline \multicolumn{4}{|l|}{ Age group } \\
\hline$\leq 52$ & $87(100)$ & 0 & $3.24(0.07)$ \\
\hline$>52$ & $79(96.3)$ & $3(3.7)$ & \\
\hline \multicolumn{4}{|l|}{$\mathrm{O}_{2}$ requirement } \\
\hline Yes & $89(96.7)$ & $3(3.3)$ & $2.56(0.11)$ \\
\hline No & $77(100)$ & 0 & \\
\hline \multicolumn{4}{|l|}{ Intubated } \\
\hline Yes & $8(88.9)$ & $1(11.1)$ & $4.75(0.03)^{*}$ \\
\hline No & $158(98.8)$ & $2(1.3)$ & \\
\hline \multicolumn{4}{|l|}{ ICU stay } \\
\hline Yes & $30(96.8)$ & $1(3.2)$ & $0.46(0.50)$ \\
\hline No & $136(98.6)$ & $2(1.4)$ & \\
\hline \multicolumn{4}{|l|}{ Group } \\
\hline Steroid & $92(98.9)$ & $1(1.1)$ & $0.58(0.45)$ \\
\hline Non steroid & $74(97.4)$ & $2(2.6)$ & \\
\hline \multicolumn{4}{|l|}{ High/Low } \\
\hline High dose & $38(97.4)$ & $1(2.6)$ & $1.44(0.49)$ \\
\hline Low dose & $54(100)$ & 0 & \\
\hline No Steroid & $74(97.4)$ & $2(2.6)$ & \\
\hline \multicolumn{4}{|l|}{ Favipiravir } \\
\hline Yes & $10(90.9)$ & $1(9.1)$ & $3.61(0.06)$ \\
\hline No & $156(98.7)$ & $2(1.3)$ & \\
\hline \multicolumn{4}{|l|}{ Triple therapy } \\
\hline Yes & $17(100)$ & 0 & $0.34(0.56)$ \\
\hline No & $149(98)$ & $3(2)$ & \\
\hline \multicolumn{4}{|l|}{ Hydroxychloroquine } \\
\hline Yes & $49(100)$ & 0 & $1.25(0.26)$ \\
\hline No & $117(97.5)$ & $3(2.5)$ & \\
\hline \multicolumn{4}{|l|}{ Tocilizumab } \\
\hline Yes & $24(100)$ & 0 & $0.51(0.48)$ \\
\hline No & $142(97.9)$ & $3(2.1)$ & \\
\hline \multicolumn{4}{|l|}{ Gender } \\
\hline Male & 102 (99) & $1(1)$ & $0.98(0.32)$ \\
\hline Female & $64(97)$ & $2(3)$ & \\
\hline
\end{tabular}

${ }^{*}$ indicates significant $p$ value.

likely to be in the ICU, require mechanical ventilation and have underlying comorbidities. There is no difference in the mean age between the different groups. However, those being treated with steroid were more likely to have a high Sequential Organ Failure Assessment (SOFA) score $(0.37 \pm 0.68,0.36 \pm 0.67$ and $0.04 \pm 0.34$, for low-dose, high-dose steroid and no steroid groups, respectively $(p=0.001)$.

There was a significant difference in the hospital Length of stay (LOS) and the ICU LOS (Table 2). In addition, there is a significant difference in the use of azithromycin, favipiravir, and triple anti-viral therapy (PEGylated interferon, ribavirin, lopinavir/ ritonavir). The low-dose steroid group was more likely to be on triple therapy than the high-dose steroid group (29.6\% vs. $2.6 \%$; $p<0.0001)$ and less likely to be on favipiravir (3.7\% vs. $20.5 \%$; $p<0.0001)$.

We tried to do multivariate analysis. However, Cox regression was not possible as the mortality rate was very low $(3 / 169 ; 1.78 \%)$ and none of the multivariate methods would be possible as the model will not converge. However, a crosstabs and $t$-tests to show the differences are shown in Table 3. Only, intubation was associated risk of mortality.

\section{DISCUSSION}

The use of corticosteroid for the therapy of patients admitted with COVID-19 had been approved by the Saudi ministry of health on June 17,2020 . The protocol called for the use of steroid in adults with a respiratory rate $\geq 30 / \mathrm{min}$, blood oxygen saturation equal to or less than $93 \%$, a ration of the $\mathrm{PaO}_{2} / \mathrm{FiO}_{2}$ of less than 300 , the presence of lung infiltration of $50 \%$ within $24-48 \mathrm{~h}$ [20]. In a recent study from Saudi Arabia, 40 patients with severe COVID-19 were treated with a combination of corticosteroid and tocilizumab and the mortality rate was $15 \%$ [13]. The patients in the high-dose steroid had a higher rate of the use of favipiravir than those in the low-dose steroid. The use of favipiravir was 38\% in a study from Tokyo, Japan [21]. In a recent randomized controlled trial, the use of favipiravir was associated with shorter duration of illness in those with mild-moderate COVID-19 [22]. The mean days of ICU and hospital stay was 6 and 22 days in a study from Tokyo [21]. However, the mean $( \pm S D)$ of ICU and hospital stay were $10.30( \pm 17.56)$ and $18(5 \pm 8.1)$ for low-dose steroid and were 12 (38.7) and 5.95 (6.26) for high-dose steroid, respectively.

The use of high-dose corticosteroid is not well studied in relation to COVID-19 cases. In a study from Tokyo, Japan, 16 (66.7\%) of 24 patients received high-dose methylprednisolone (500-1000 mg) [21]. In a report of two cases, there was a suggestion that high-dose steroid might be of benefit in low resource countries [23]. In a retrospective study comparing high-dose versus conventional doses of corticosteroid, it was noted that high-dose group were more likely to have comorbid conditions [24]. The study showed that the risk of mortality and the need for mechanical ventilation was higher in the high-dose corticosteroid even after adjusting for baseline characteristics [24].

In our study, the ICU admitted patients were prescribed high-dose steroid and this can be explained by their illness severity, although most of them had required oxygen but were less to be mechanically intubated and had a shorter LOS. Moreover, underlying comorbidities was almost similar between the high versus the low steroid group except for hypertensive patients were more in low steroid group. In addition, the use of antiviral agents was more with low steroid group. However, our study is a retrospective study and thus no firm conclusions could be drawn and the role of high-dose steroid remains to be established if any. Cox regression was not possible as the mortality rate was very low (1.78\%) and none of the multivariate methods would be possible as the model will not converge. However, in $t$-test only, intubation was associated risk of mortality. 


\section{CONFLICTS OF INTEREST}

The authors declare they have no conflicts of interest.

\section{AUTHORS' CONTRIBUTION}

All authors contributed to the data gathering, analysis, or drafting the first draft. All authors approved the final draft.

\section{FUNDING}

No financial support was provided.

\section{REFERENCES}

[1] Chen N, Zhou M, Dong X, Qu J, Gong F, Han Y, et al. Epidemiological and clinical characteristics of 99 cases of 2019 novel coronavirus pneumonia in Wuhan, China: a descriptive study. Lancet 2020;395;507-13.

[2] Zhou F, Yu T, Du R, Fan G, Liu Y, Liu Z, et al. Clinical course and risk factors for mortality of adult inpatients with COVID-19 in Wuhan, China: a retrospective cohort study. Lancet 2020;395; 1054-62.

[3] Nicastri E, D’Abramo A, Faggioni G, De Santis R, Mariano A, Lepore L, et al. Coronavirus disease (COVID-19) in a paucisymptomatic patient: epidemiological and clinical challenge in settings with limited community transmission, Italy, February 2020. Euro Surveill 2020;25;2000230.

[4] Al-Omari A, Alhuqbani WN, Zaidi ARZ, Al-Subaie MF, AlHindi $\mathrm{AM}, \mathrm{Abogosh} \mathrm{AK}$, et al. Clinical characteristics of non-intensive care unit COVID-19 patients in Saudi Arabia: a descriptive cross-sectional study. J Infect Public Health 2020;13;1639-44.

[5] Al Mutair A, Alhumaid S, Alhuqbani WN, Zaidi ARZ, Alkoraisi S, Al-Subaie MF, et al. Clinical, epidemiological, and laboratory characteristics of mild-to-moderate COVID-19 patients in Saudi Arabia: an observational cohort study. Eur J Med Res 2020;25;61.

[6] AlJishi JM, Alhajjaj AH, Alkhabbaz FL, AlAbduljabar TH, Alsaif A, Alsaif $\mathrm{H}$, et al. Clinical characteristics of asymptomatic and symptomatic COVID-19 patients in the Eastern Province of Saudi Arabia. J Infect Public Health 2021;14;6-11.

[7] Tirupathi R, Muradova V, Shekhar R, Salim SA, Al-Tawfiq JA, Palabindala V. COVID-19 disparity among racial and ethnic minorities in the US: a cross sectional analysis. Travel Med Infect Dis 2020;38;101904.

[8] Al-Tawfiq JA, Leonardi R, Fasoli G, Rigamonti D. Prevalence and fatality rates of COVID-19: what are the reasons for the wide variations worldwide?. Travel Med Infect Dis 2020;35; 101711 .

[9] Siddiqi HK, Mehra MR. COVID-19 illness in native and immunosuppressed states: a clinical-therapeutic staging proposal. J Heart Lung Transplant 2020;39;405-7.

[10] Zhang W, Zhao Y, Zhang F, Wang Q, Li T, Liu Z, et al. The use of anti-inflammatory drugs in the treatment of people with severe coronavirus disease 2019 (COVID-19): the perspectives of clinical immunologists from China. Clin Immunol 2020;214;108393.

[11] Zhao D, Yao F, Wang L, Zheng L, Gao Y, Ye J, et al. A comparative study on the clinical features of coronavirus 2019 (COVID-19) pneumonia with other pneumonias. Clin Infect Dis 2020;71;756-61.

[12] Xu X, Han M, Li T, Sun W, Wang D, Fu B, et al. Effective treatment of severe COVID-19 patients with tocilizumab. Proc Natl Acad Sci U S A 2020;117;10970-5.

[13] AlBahrani S, Al-Tawfiq JA, Alshaer AR, Shilash A, Alswefy K, Al-Zayer RS, et al. A case series of severe hospitalized COVID-19 patients treated with tocilizumab and glucocorticoids: a report from Saudi Arabian hospital. J Epidemiol Glob Health 2021.

[14] Yang X, Yu Y, Xu J, Shu H, Xia J, Liu H, et al. Clinical course and outcomes of critically ill patients with SARS-CoV-2 pneumonia in Wuhan, China: a single-centered, retrospective, observational study. Lancet Respir Med 2020;8;475-81.

[15] Auld SC, Caridi-Scheible M, Blum JM, Robichaux C, Kraft C, Jacob JT, et al. ICU and ventilator mortality among critically ill adults with coronavirus disease 2019. Crit Care Med 2020;48;e799-e804.

[16] McCreary EK, Pogue JM. Coronavirus disease 2019 treatment: a review of early and emerging options. Open Forum Infect Dis 2020; 7;ofaa105.

[17] Russell CD, Millar JE, Kenneth Baillie J. Clinical evidence does not support corticosteroid treatment for 2019-nCoV lung injury. Lancet 2020;395;473-5.

[18] RECOVERY Collaborative Group; Horby P, Lim WS, Emberson JR, Mafham M, Bell JL, et al. Dexamethasone in hospitalized patients with Covid-19-preliminary report. N Engl J Med 2021;384;693-704.

[19] Al-Tawfiq JA, Sattar A, Al-Khadra H, Al-Qahtani S, Al-Mulhim $\mathrm{M}, \mathrm{Al}$-Omoush O, et al. Incidence of COVID-19 among returning travelers in quarantine facilities: a longitudinal study and lessons learned. Travel Med Infect Dis 2020;38;101901.

[20] Saudi Ministry of Health. Saudi MoH Protocol for Patients Suspected of/Confirmed with COVID-19. Supportive care and antiviral treatment of suspected or confirmed COVID-19 infection. 2020. Available from: https://www.moh.gov.sa/Ministry/ MediaCenter/Publications/Documents/MOH-therapeuticprotocol-for-COVID-19.pdf (accessed on June 19, 2020).

[21] Banno A, Hifumi T, Okamoto H, Masaki M, Seki K, Isokawa S, et al. Clinical characteristics and outcomes of critically ill COVID-19 patients in Tokyo: a single-center observational study from the first wave. BMC Infect Dis 2021;21;163.

[22] Udwadia ZF, Singh P, Barkate H, Patil S, Rangwala S, Pendse A, et al. Efficacy and safety of favipiravir, an oral RNA-dependent RNA polymerase inhibitor, in mild-to-moderate COVID-19: a randomized, comparative, open-label, multicenter, phase 3 clinical trial. Int J Infect Dis 2021;103;62-71.

[23] Edara L, Suvvari TK, Kutikuppala LVS. High dose steroid therapy to prevent severe hypoxia in COVID-19 patients: a potential solution for low resource clinical setting. Cureus 2020;12;e12330.

[24] Monreal E, de la Maza SS, Natera-Villalba E, Beltrán-Corbellini Á, Rodríguez-Jorge F, Fernández-Velasco JI, et al. High versus standard doses of corticosteroids in severe COVID-19: a retrospective cohort study. Eur J Clin Microbiol Infect Dis 2021;40;761-9. 